\title{
XXI. A portable instrument for measuring magnetic fields. With some observations on the strength of the stray fields of dynamos
}

\section{Edwin Edser \& Herbert Stansfield}

To cite this article: Edwin Edser \& Herbert Stansfield (1892) XXI. A portable instrument for measuring magnetic fields. With some observations on the strength of the stray fields of dynamos, Philosophical Magazine Series 5, 34:207, 186-189, DOI: 10.1080/14786449208620306

To link to this article: http://dx.doi.org/10.1080/14786449208620306

曲 Published online: 07 May 2010.

Submit your article to this journal

Ш Article views: 3

View related articles $\sqsubset$ 
cannot suppose that imperceptible traces of grease, ineradicable as they may be, would produce complete and delicate outlines. The cleaning off of impressions may at first seem to indicate a deposit; but this renewal of the surface might rather be like smoothing out an indented tin-foil surface: such a view might explain the case where a blank overelectrified disk is developed into fine detail. The electrified figures seem to point to a bombardment, which produces a molecular change, the intensity of electricity bringing about quickly what may also be done by slow persistent action of mechanical pressure. At present it seems as if most of the phenomena cannot be drawn out from the unknown region of molecular agency.

While experimenting I was not within reach of references to former researches, but I have since done my best to find them out, and to indicate all I have learnt in the body of my paper.

Poggendorff, vol. lvii. p. 492 ; translated in Archives de l'Electricité, 1842 , p. 647.

Riess' Electrische Hauchfiguren in Repertorium der Plyysik; translated in Archives de l'Electricité, 1842, p. 591.

Riess' Die Lehre, von der Reibungs Electricität, vol. ii. pp. 221-224.

Mascart, Electricité Statique, vol. ii. p. 177.

Taylor's Scientific Memoirs, vol. iii.

XXI. A Portable Instrument for Measuring Magnetic Fields. With some Observations on the Strength of the Stray Fields of Dynamos. By Edwin Edser and Herbert Stansfield*.

[Plates III. \& IV.]

THIS instrument was constructed for the purpose of giving 1 direct readings for the strength of magnetic fields, such as are found in the neighbourhood of Dynamos ; thus avoiding the inconveniences attending the Ballistic method. Portability, a considerable range, and a fair degree of accuracy were the qualities sought. The instrument, as now constructed, whilst satisfying the first of these conditions, may be used to measure any field from 1 line per centimetre upwards, with an error of only about 2 per cent.; the only accessories required being a dry cell and a resistance-box.

* Communicated by the Physical Society : read May 13, 1892. 
In principle it is the inversion of the D'Arsonval galvanometer; the torsion necessary to restore a coil, through which a constant current circulates, to its normal position, parallel to the direction of the lines of force, furnishing readings proportional to the field at the position of the coil*.

A diagram of the instrument is shown in fig. 1 (Plate III.). A B is a small coil, oblong in shape, wound of No.44 B.W.G. copper wire, and suppported half on each side of a sheet of mica. It is suspended from each end by strips, 10 centim. long, of rolled German-silver wire, each strip having a loop which is passed over a small brass hook riveted on to the mica, and in electrical communication with a terminal of the coil. The strip CA is in electrical comexion with the case of the instrument at $\mathrm{C}$, whilst the strip D B is insulated from it at $D$ by an ebonite plug, attached to the torsion-head E. Inside this latter is a commutator for automatically reversing the current, so as to take readings on each side of the zero. It consists of four semicircular strips of copper, cross connected as shown in fig. $2, a$ and $b$ being connected to the two battery terminals. Two springs, one soldered to the case, the other insulated from it, but connected to the end of the suspending strip D B, press on these semicircular strips. When the torsion-head is at zero no current passes, the springs then being at $c$ and $d$ respectively (fig. 2). To take a reading the torsion-head is turned, thus sending the current through the coil. Should the latter be deflected in the wrong direction, the current can be reversed by means of the plug contact, $\mathrm{P}$, attached to the battery leads. Readings are taken on each side of zero in order to eliminate any error due to imperfect balancing of the coil; an aluminium pointer $G$, attached to the coil, being always brought by the torsion to the zero position on a small scale.

In order to obtain at once a spring-suspension and an adjustment for the torsion of the strip, a particular form of geometrical slide is used. $\mathrm{A} \mathrm{A}^{\prime}$ (fig. 3) is a thick brass tube, turned at $\mathrm{BB}^{\prime}$ to a slightly conical plug to fit the tube of

* After the completion of this instrument our attention was called to some experiments of Messrs. Siemens aud Halske, in which the same principle was used.

"In order to measure the intensities of the rotary field, a coil was hung in the centre of the ring, in such a way that its magnetic axis was perpendicular to the measured direction of the resulting warnetic axis of the ring. The coil was then excited by a continnous current, and was kept in position by a spring. The torque of the spring served as a measure of the intensity." "Deduction and Experiments on Rotary Currents." A. du Bois Reymond, 'Electrical Review,' June 5, 1891, vol. xxviii. No. 706 . 

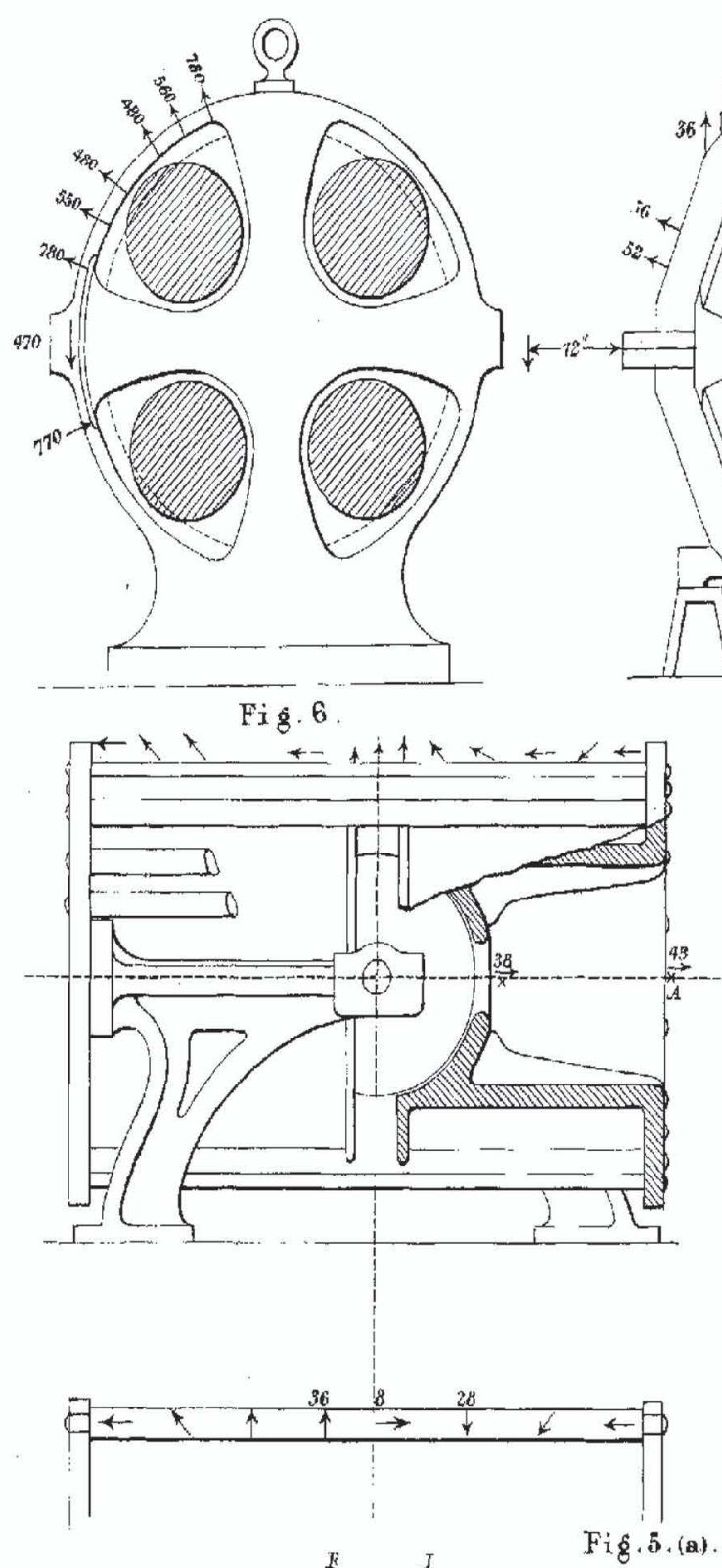

(1)

II

$\bar{r}$ (m)

-
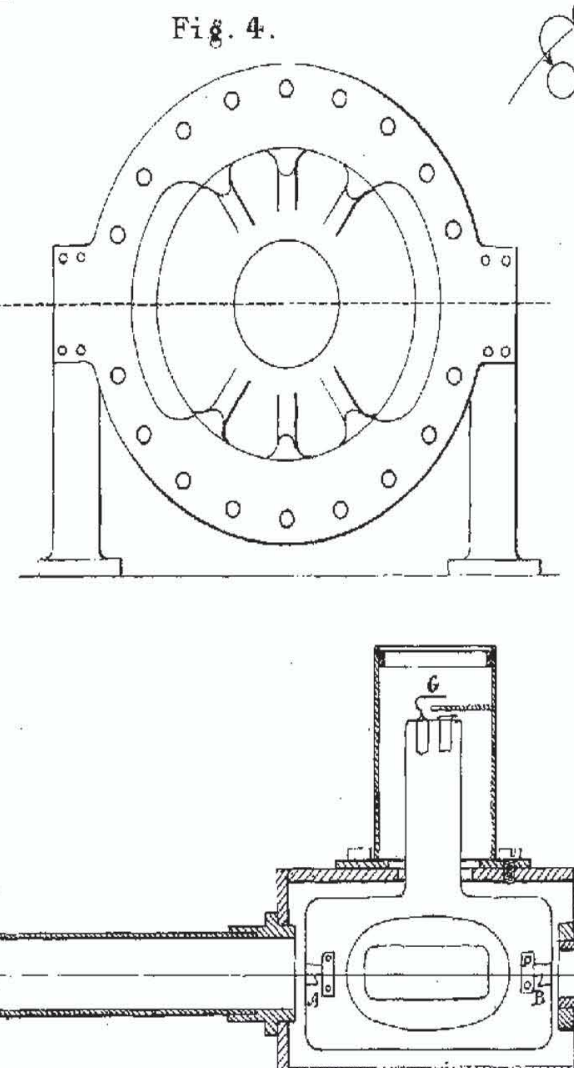

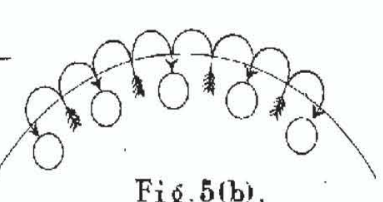

Fì $.5(b)$.

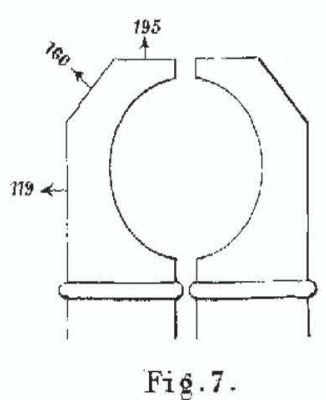

Phil.Mar. S. 5.Vol 34. Fi. III.

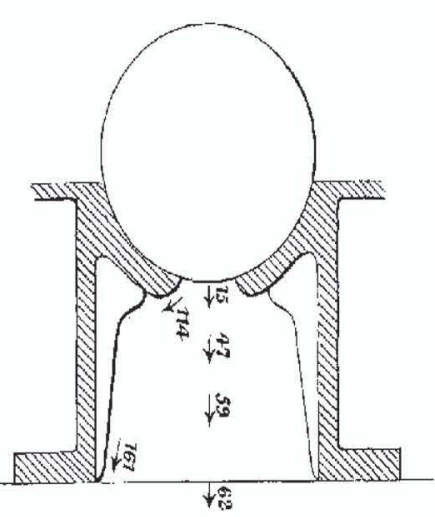

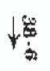

愢
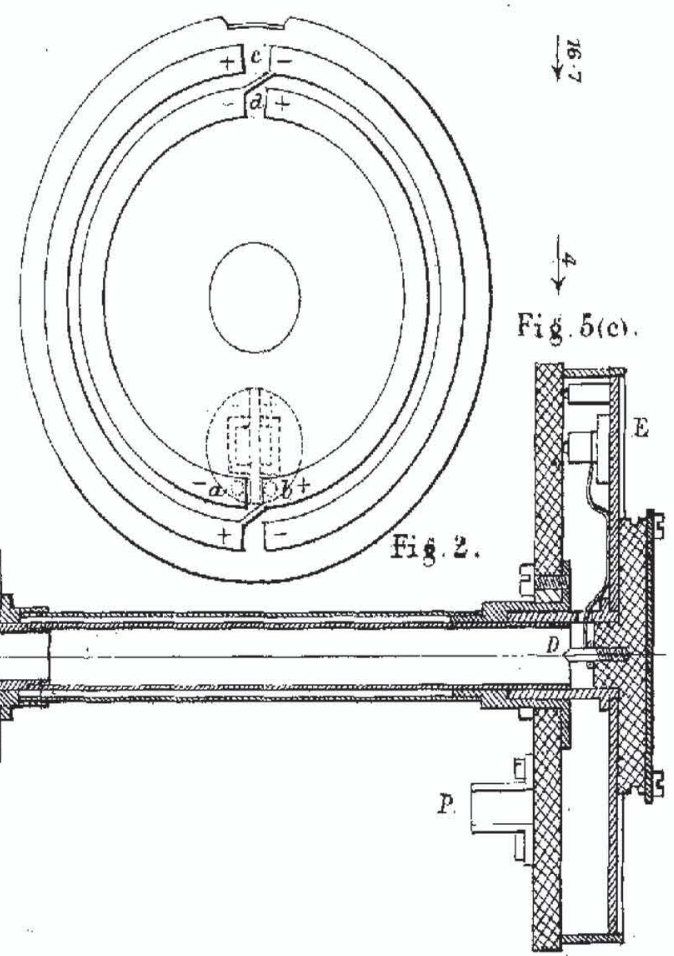

Fig. 1.

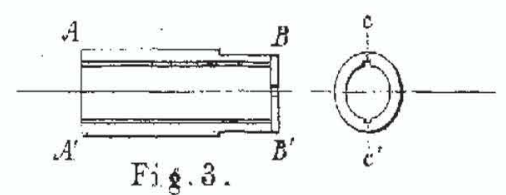


the instrument (fig. 1). Two grooves (seen in plan at $\mathrm{CC}^{\prime}$ ) are made along this tube, a cross head F (fig. 1) on the screw $\mathrm{E} F$ fitting into them. This screw is drilled along its whole length to admit a thick wire $\mathrm{H} \mathrm{I} \mathrm{C}$, the latter having a cross head $I$, also fitting into the longitudinal grooves. These two cross heads are then connected to the two ends of a spiral spring, in such a mauner that they are pressed by it against opposite sides of the grooves. The suspending strip being connected to the central wire $\mathrm{HIC}$ at $\mathrm{C}$, its tension can be increased or diminished by means of the nut $K$, without altering the position of the coil. Any sudden jerk will also be taken by the spring, thus obviating the risk of stretching the suspending strip. Scratches on the wire $\mathrm{HIC}$ near $\mathrm{H}$ indicate the tension used.

As a source of current a Hellesen dry cell is used. When joined up through $50 \mathrm{ohms}$ the E.M.F. of the cell is practically constant, whilst its internal resistance is negligible*.

The resistance of the instrument having been made up to 50 ohms, it follows that its sensitiveness can be varied by introducing an independent resistance in the circuit.

Let $\mathrm{C}=$ constant of instrument $\left(i . e\right.$. field for $1^{\circ}$ of torsion, with no external resistance in circuit);

$n=$ multiple of $50 \mathrm{ohms}$ in circuit, exclusive of resistance of instrument;

then

$\theta=$ mean angular torsion;

Field in C.G.S. measure $=\mathrm{C}(n+1) \theta$.

$\mathrm{C}$ was determined, and the instrument calibrated, between the coils of a galvanometer of the Gaugain type through which a known current was passed. For an E.M.F. of 1.45 in the dry cell it was found to be $\cdot 293$. The error shown in the calibration was always below 2 per cent.

By permission of the Committee of Experts, and of a number of the firms exhibiting, a series of measurements were made at the Electrical Exhibition, Crystal Palace. The results obtained are shown in the remaining figures.

Fig. 1 (Plate IV.) shows the fields measured at various distances from different dynamos, the distances plotted as abscissæ and the fields as ordinates. It is noticeable that machines of the multipolar type show a much steeper curve than other dynamos. This is especially noticeable in the case of the Gulcher Dynamo curve $(G)$.

* See Electrotechnische Zeitschrift, August 1, 1890, vol. ii. No. 31. Republished in pamphlet form by Siemens Bros. and Co., Itd. We have independently verified these results. 
Phi1.Mag. S. 5.Vo1.34. PI. IV
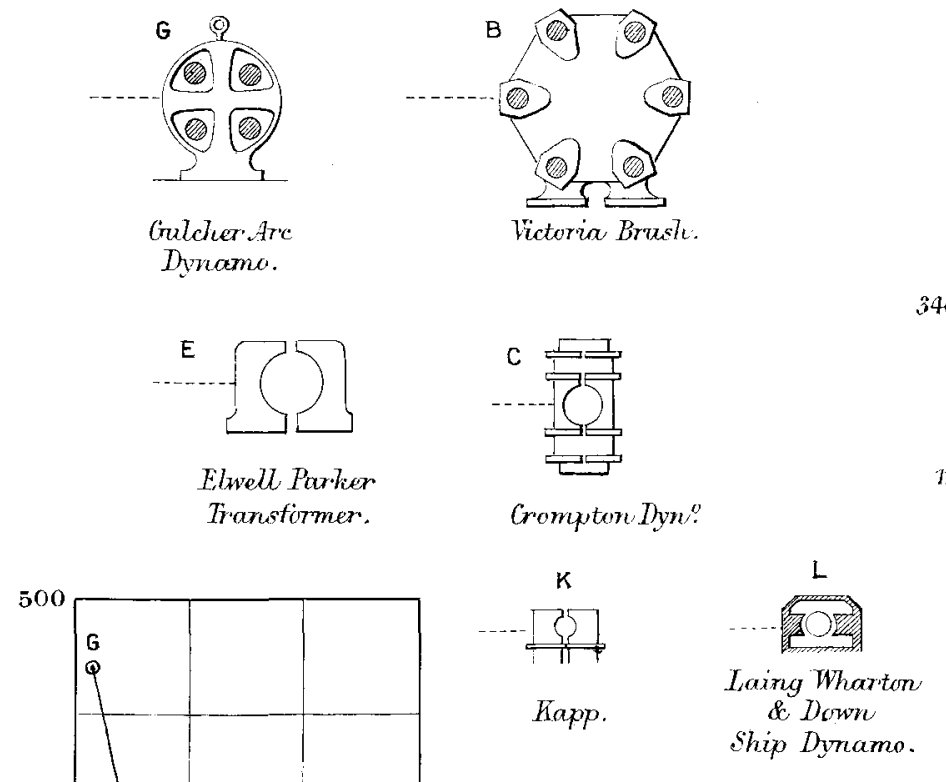

Dyno

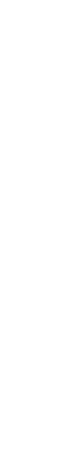

$T$

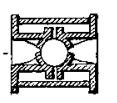

Thomson-Hotwstor Arc laght Dyramo.

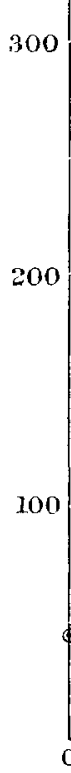

200
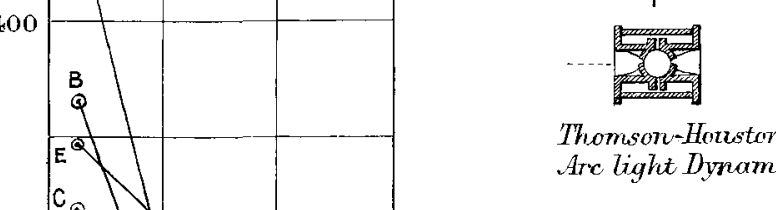
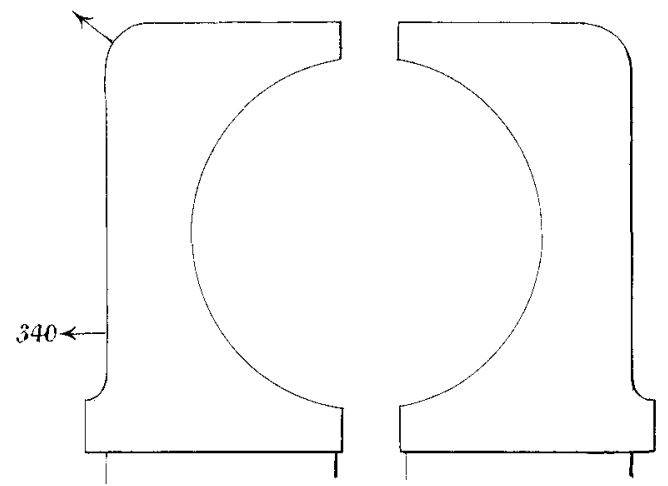

$1020+1010$

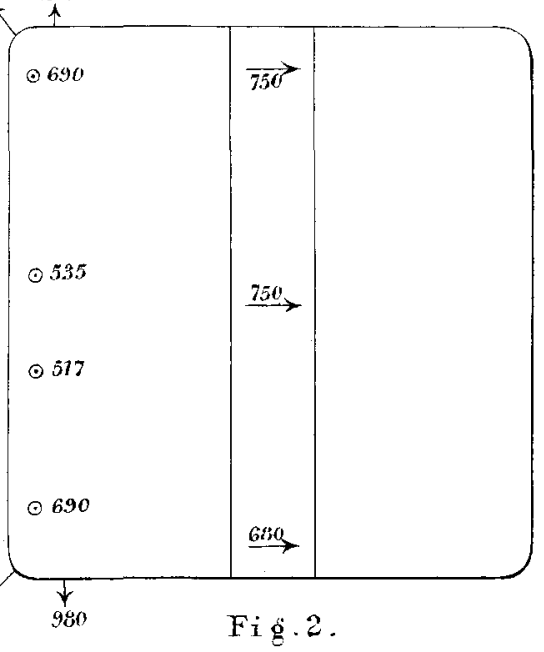

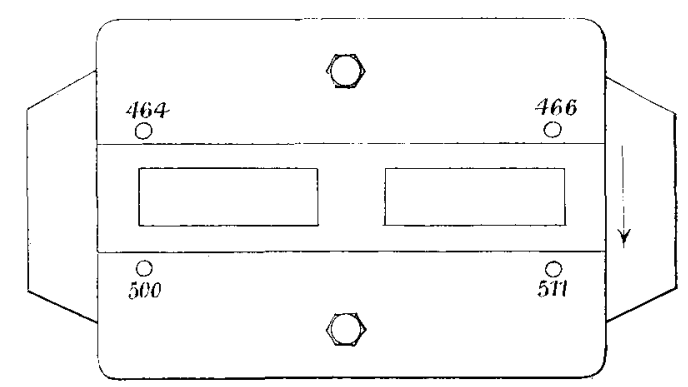

Fig. 3

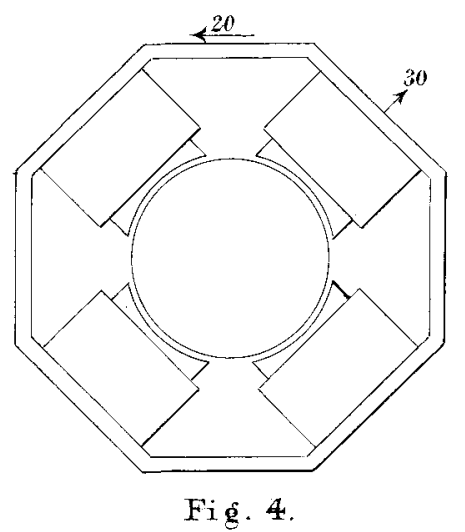

The Gurves in all cases represent the filling off of the ficlds at points in directions at right angles to the accs of the arruatures. (The dotted lines shew the directions.)

\footnotetext{
Fig. I. Mintern Bros.lith.
} 
Fig. 4 (Plate III.) shows the fields round Mr. Kapp's 8 -pole machine. They are noticeably small.

Fig. 2 (Plate IV.) shows the effect of edges, corners, \&c. on the strength of field. On the flat surface of the pole-piece the field was about 600 (varying between 517 and 690), on the edges increased to about 1000 , whilst on the corners it reached a strength of over 1100 C.G.S. lines per centimetre.

Fig. 3 (Plate IV.) shows the deformation of the stray field produced by the armature reactions. The measurements were made on an Elwell-Parker Motor. The strength of field on the trailing edge was about 460 , whilst that on the leading edge was about 500 .

Fig. 6 (Plate III.) shows various measurements made on the Gulcher Dynamo; Fig. 7 (same Plate) gives the field near one of Mr. Kapp's Dynamos ; Fig. 4 (Plate IV.) shows the fields at two positions of a Laing, Wharton, and Down shielded dynamo.

Some curious effects of armature reactions are noticeable on the Thomson-Houston Dynamo (fig. 5, Plate III.). As the bars in this machine act as a yoke, the result is due to combined magnetic leakage and armature reaction.

By the kindness of Mr. Harrison we were enabled to make some experiments on a watch, previously unmagnetized, which be lent us. We found that a field of about 10 had no appreciable effect on its rate of going, but that after being subjected to a field of about 40 it lost about 8 minutes per day; and even after being demagnetized in an alternating field it still continued very erratic in its actions. Of the dynamos whose fields we have measured, with the exception of the ThomsonHouston, Ship's Dynamo (Laing, Wharton, and Down), and Mr. Kapp's large Multipolar, it would not be safe to go nearer than about 2 feet*. Moreover, with a watch with a steel balance-wheel (the one experimented upon had a brass one), even greater precautions might have to be observed.

Finally, we wish to record our thanks to Mr. Harrison for allowing us to experiment on his watch; to Mr. Barton for his assistance in constructing the instrument; and to Messrs. Crompton, Kapp, Laing, Wharton, and Down, the Gulcher Company, the Electric Construction Corporation, and MajorGeneral Festing, for permission to experiment on their various dynamos, and also to publish the results.

* One could not safely go within three feet of the Elwell-Parker Continuous Current Transformer. 